AUTHOR CORRECTION nitride and transition metal dichalcogenides: from monolayer

\title{
to bulk
}

\author{
Akash Laturia, Maarten L. Van de Put (D) and William G. Vandenberghe \\ npj 2D Materials and Applications (2020)4:28 ; https://doi.org/10.1038/s41699-020-00163-3
}

Correction to: npj 2D Materials and Applications https://doi.org/ 10.1038/s41699-018-0050-x, published online 8 March 2018

The authors became aware of a mistake in the original version of the paper in which they mistakenly assumed a $2 \mathrm{Hb}$ polytype $(\mathrm{P}$ $\overline{6} \mathrm{~m} 2$ space group) for the Mo- and $\mathrm{W}$ - based TMDs, but these are actually $2 \mathrm{Hc}$ polytype (P63/mmc space group) [Phys. Rev. B, $69: 134111,(2004)]$. As a result of this, the following changes have been made to the original version of this Article:

The fifth sentence of the abstract originally read "Overall, the out-of-plane dielectric constant of the TMDs and h-BN increases by around $15 \%$ as the number of layers is increased from monolayer to bulk, while the in-plane component remains unchanged." In the corrected version, "around 15\%" is replaced by "less than $15 \%$ ".

The third sentence of the sixth paragraph of the Results and discussion originally stated "Mo-based TMDs show an increase of $15 \%$ in the out-of-plane dielectric constant when going from monolayer to bulk while W-based TMDs show an increase of about $5 \%$ ". In the corrected version, "show an increase of $15 \%$ " is replaced by "show an increase of 13\%".

The last sentence of the seventh paragraph of the "Results and Discussion" originally stated "Indeed, we find that the ionic response in the in-plane direction reduces from 53.7 to 12.30 when we theoretically convert monolayer HfS2 from the 1T to the $2 \mathrm{H}$ structure". In the corrected version, "from 53.7 to 12.30 " is replaced by "from 53.7 to 14.70 ".

The seventh sentence of the first paragraph of the "Details of the ab initio calculations" section of the Methods originally read "The value of $n$ which results in converged dielectric constants for bulk $2 \mathrm{H}$ TMDs and h-BN turned out be 8 , whereas, its counterpart for bulk 1T TMDs is 16 ". The corrected version reads "The value of $n$ which results in converged dielectric constants for bulk $2 \mathrm{H}$ TMDs, h-BN, and 1T TMDs turns out to be 12, 8 , and 16, respectively".

The Data availability originally read "The data that support the findings of this study are available at http://repository.nomad-coe. eu/NomadRepository-1.1/search/index.zul". The corrected version reads "The data that supports the findings of this study is available at https://doi.org/10.17172/NOMAD/2020.07.17-1".

In Table 2, most values of out-of-plane $(\epsilon \perp)$ and in-plane $(\epsilon \|)$ dielectric constants of Mo-based and W-based TMDs are updated, as well as $\epsilon_{0,1}$ of bilayer $\mathrm{HfSe}_{2}(\mathrm{~T})$. The correct version of Table 2 appears below:
Table 2. TMDs: in-plane and out-of-plane macroscopic dielectric constant of monolayer, bilayer and bulk.

Material $1 \mathrm{~L}\left(\epsilon_{\infty}\right) \quad 1 \mathrm{~L}\left(\epsilon_{0}\right) \quad 2 \mathrm{~L}\left(\epsilon_{\infty}\right) \quad 2 \mathrm{~L}\left(\epsilon_{0}\right) \quad$ Bulk $\left(\epsilon_{\infty}\right) \quad$ Bulk $\left(\epsilon_{0}\right)$

$\overline{\perp \|} \overline{\perp \|} \overline{\perp \|} \overline{\perp \|} \overline{\perp \|} \stackrel{2 \|}{\perp \|}$

$\begin{array}{lllllllllllll}\mathrm{MoS}_{2}(\mathrm{H}) & 6.1 & 15.4 & 6.2 & 15.5 & 6.5 & 15.6 & 6.6 & 15.7 & 6.9 & 15.8 & 6.9 & 15.9\end{array}$

$\begin{array}{lllllllllllll}\mathrm{MoSe}_{2}(\mathrm{H}) & 7.2 & 16.8 & 7.2 & 17.4 & 7.6 & 17.0 & 7.7 & 17.5 & 8.1 & 17.2 & 8.2 & 17.7\end{array}$

$\begin{array}{lllllllllllll}\mathrm{MoTe}_{2}(\mathrm{H}) & 8.9 & 19.7 & 9.1 & 21.6 & 9.4 & 19.9 & 9.8 & 21.7 & 10.1 & 20.1 & 10.4 & 21.9\end{array}$

$\begin{array}{lllllllllllll}\text { WS2(H) } & 6.1 & 14 & 6.1 & 14 & 6.2 & 14.2 & 6.2 & 14.2 & 6.4 & 14.4 & 6.4 & 14.4\end{array}$

$\begin{array}{lllllllllllll}\text { WSe }_{2}(\mathrm{H}) & 7.4 & 15.3 & 7.4 & 15.6 & 7.5 & 15.5 & 7.6 & 15.7 & 7.7 & 15.6 & 7.8 & 15.9\end{array}$

$\begin{array}{lllllllllllll}\mathrm{HfS}_{2}(\mathrm{~T}) & 5.6 & 10.2 & 6.6 & 53.6 & 5.6 & 10.2 & 6.3 & 51.3 & 5.8 & 10.4 & 6.5 & 48.9\end{array}$

$\begin{array}{lllllllllllll}\mathrm{HfSe}_{2}(\mathrm{~T}) & 6.7 & 13.9 & 7.6 & 83.0 & 6.9 & 13.9 & 7.7 & 77.0 & 7.2 & 13.9 & 7.8 & 71.2\end{array}$

$\begin{array}{lllllllllllll}\mathrm{ZrS}_{2}(\mathrm{~T}) & 5.7 & 11.2 & 6.8 & 66.7 & 5.9 & 11.3 & 6.9 & 61.3 & 6.2 & 11.4 & 7.0 & 65.3\end{array}$

which replaces the previous incorrect version:

Table 2. TMDs: in-plane and out-of-plane macroscopic dielectric constant of monolayer, bilayer and bulk.

\begin{tabular}{|c|c|c|c|c|c|c|c|c|c|c|c|}
\hline \multirow[t]{2}{*}{ Material } & \multicolumn{2}{|c|}{$1 \mathrm{~L}\left(\epsilon_{\infty}\right)$} & \multicolumn{2}{|c|}{$1 \mathrm{~L}\left(\epsilon_{0}\right)$} & \multicolumn{2}{|c|}{$2 \mathrm{~L}\left(\epsilon_{\infty}\right)$} & $2 \mathrm{~L}\left(\epsilon_{0}\right)$ & \multicolumn{2}{|c|}{ Bulk $\left(\epsilon_{\infty}\right)$} & \multicolumn{2}{|c|}{ Bulk $\left(\epsilon_{0}\right)$} \\
\hline & $\perp$ & $\|$ & $\perp$ & $\|$ & $\perp$ & $\|$ & $\perp$ & $\perp$ & $\|$ & $\perp$ & $\|$ \\
\hline & 6 & 15.1 & 6. & 15.3 & 6.8 & 15.3 & 6.81 & 7.2 & 16.1 & 7.3 & 16 \\
\hline $\mathrm{AoSe}_{2}(\mathrm{H})$ & 7.4 & 16.5 & 7.4 & 17.1 & 7.8 & 16.7 & 7.917 .3 & 8.3 & 17.3 & 8.5 & 17. \\
\hline $\mathrm{AoTe}_{2}(\mathrm{H})$ & 8.8 & 19.5 & 8.9 & 21.4 & 9.3 & 19.7 & 9.621 .6 & 10.1 & 20.5 & 10.4 & 22.2 \\
\hline $\mathrm{VS}_{2}(\mathrm{H})$ & 6.3 & 13.6 & 6.3 & 13.7 & 6.5 & 13.8 & 6.513 .9 & 6.6 & 14.5 & 6.7 & 14.6 \\
\hline$/ \mathrm{Se}_{2}(\mathrm{H})$ & 7.5 & 15.1 & 7.5 & 15.3 & 7.7 & 15.2 & 7.715 .5 & 7.8 & 15.7 & 7.9 & 16. \\
\hline 5211 & 5.6 & 10.2 & 6.6 & 53.6 & 5.6 & 10.2 & 6.351 .3 & 5.8 & 10.4 & 6.5 & 48.5 \\
\hline & 6.7 & 13.9 & 7.6 & 83.0 & 6.9 & 13.9 & & 7.2 & 13.9 & 7.8 & 71.2 \\
\hline $\mathrm{rS}_{2}(\mathrm{~T})$ & 5.7 & 11.2 & 6.8 & 66.7 & 5.9 & 11.3 & 6.961 .3 & 6.2 & 11.4 & 7.0 & 65.3 \\
\hline
\end{tabular}

In Table 3, most values of thicknesses and the in-plane lattice constants of the Mo-based and W-based TMDs are updated. The correct version of Table 3 appears below: 
Table 3. Simulation parameters used for the calculation of macroscopic dielectric constants of 2D materials.

\begin{tabular}{|c|c|c|c|c|}
\hline Material & a $(\AA)$ & $1 \mathrm{~L}[t(\AA)]$ & $2 L[t(\AA)]$ & Bulk $\left[\mathrm{d}_{i}\right]$ \\
\hline $\mathrm{MoSe}_{2}(2 \mathrm{H})$ & 3.35 & $6.49(-0.15 \%)$ & $12.98(-0.15 \%)$ & 6.48 \\
\hline $\mathrm{WS}_{2}(2 \mathrm{H})$ & 3.21 & $6.12(-0.33 \%)$ & $12.23(-0.16 \%)$ & 6.1 \\
\hline $\mathrm{WSe}_{2}(2 \mathrm{H})$ & 3.33 & $6.48(-0.15 \%)$ & $12.95(-0.15 \%)$ & 6.47 \\
\hline h-BN (H) & 2.51 & $3.17(-1.42 \%)$ & $6.31(-0.95 \%)$ & 3.12 \\
\hline $\mathrm{HfSe}_{2}(1 \mathrm{~T})$ & 3.79 & $6.13(-0.33 \%)$ & $12.24(-0.16 \%)$ & 6.11 \\
\hline $\mathrm{ZrS}_{2}(1 \mathrm{~T})$ & 3.70 & $5.74(-0.52 \%)$ & $11.46(-0.35 \%)$ & 5.71 \\
\hline
\end{tabular}

which replaces the previous incorrect version:

Table 3. Simulation parameters used for the calculation of macroscopic dielectric constants of 2D materials.

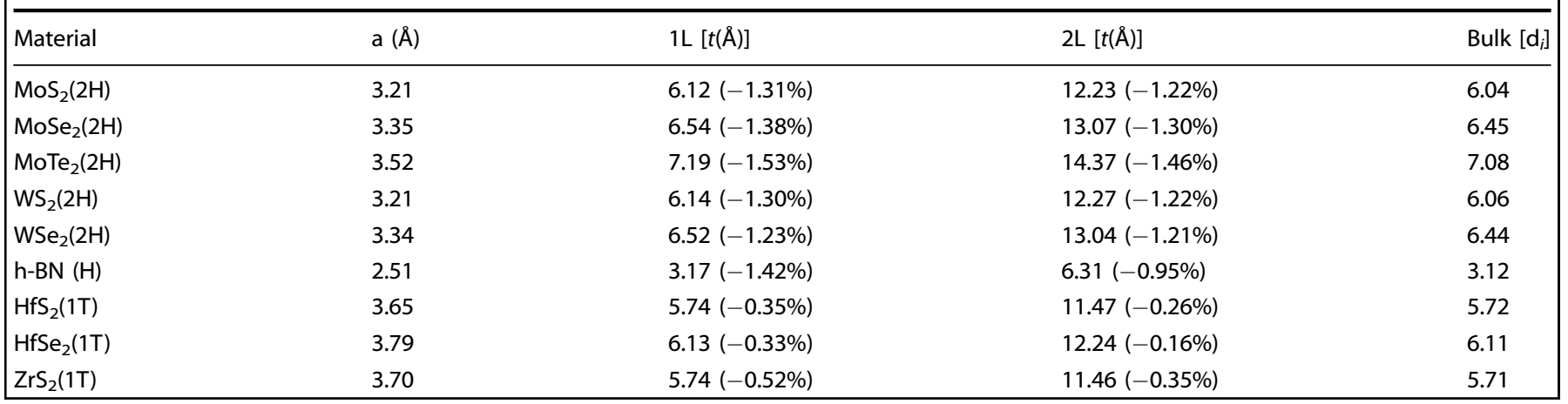

Figures 2 and 3 depict the static and optical dielectric constants for layered TMDs, respectively, with the same dataset listed in Table 2. The correct version of Fig. 2 is:
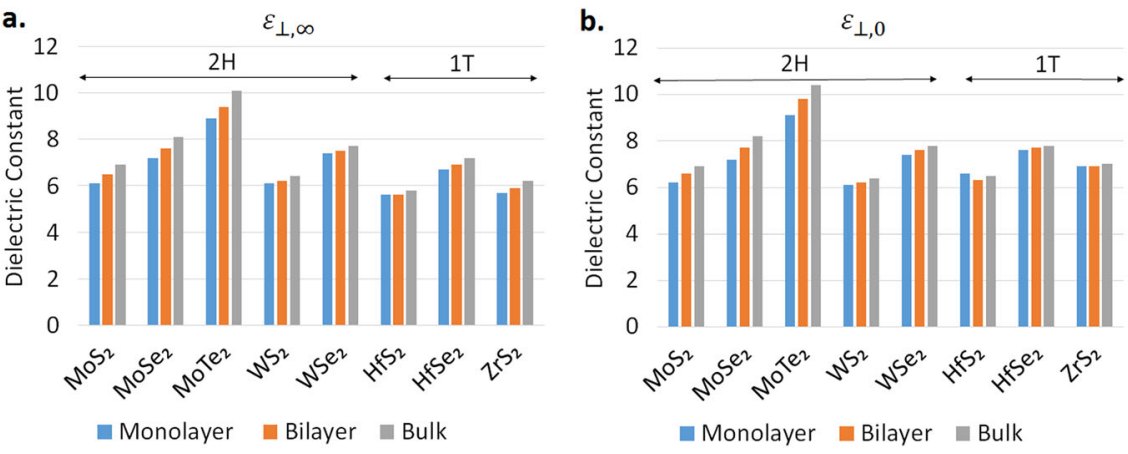

Fig. 2 
replaces the previous incorrect version:
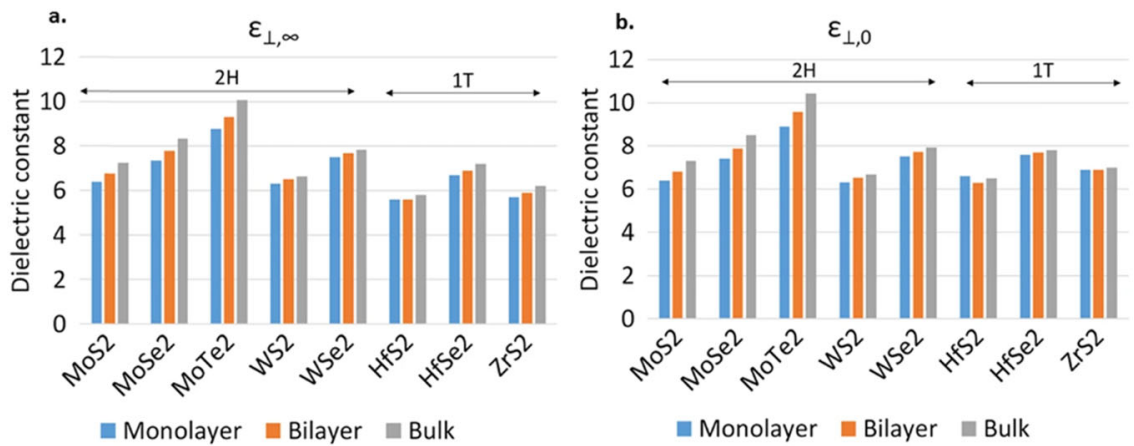

And the correct version of Fig. 3:
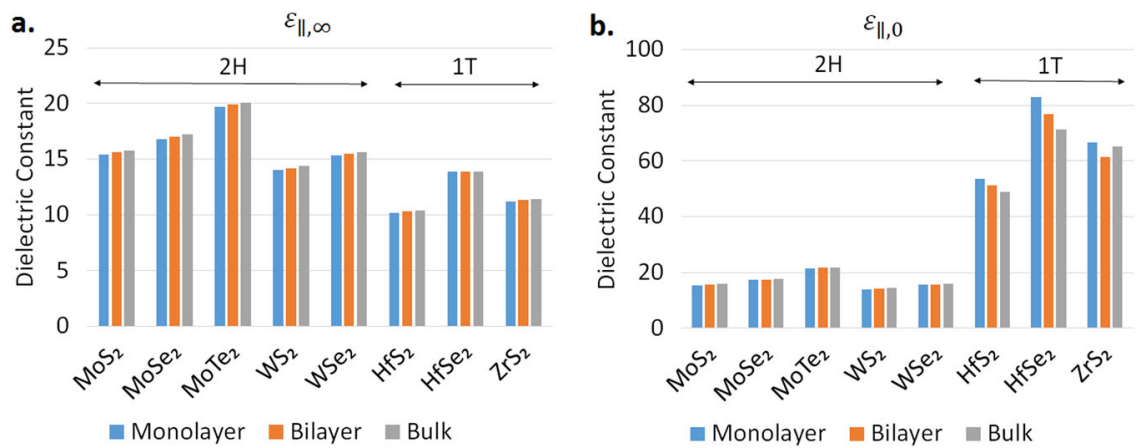

Fig. 3

replaces the previous incorrect version:
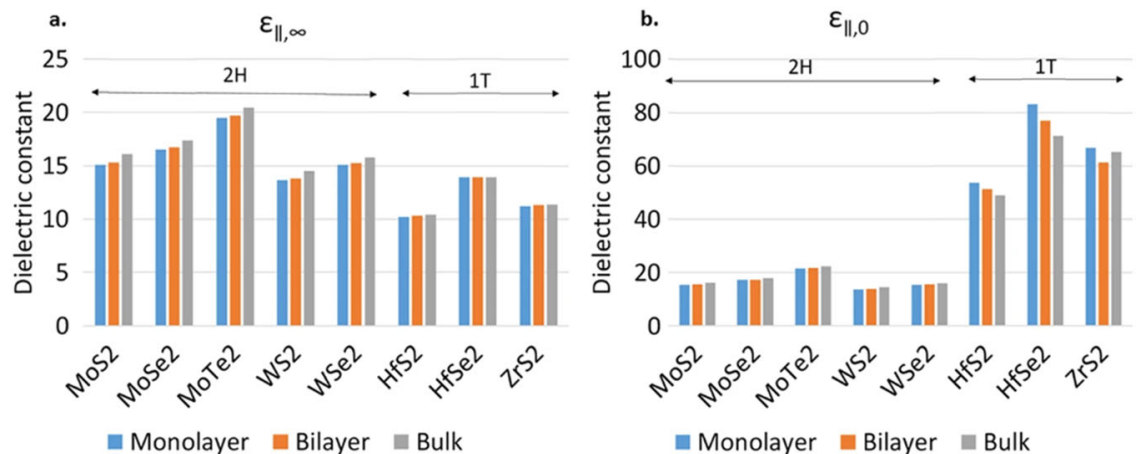

In Fig. 4, the $2 \mathrm{H}$ bilayer structure is modified. The correct version of Fig. 4 is: 
$2 \mathrm{H}$

a.

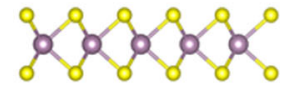

b.

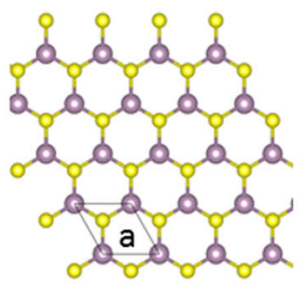

c.

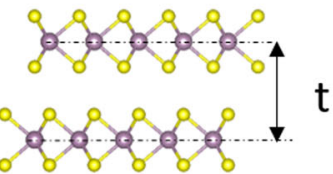

Metal
1T

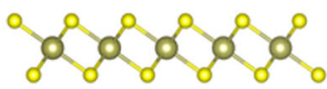

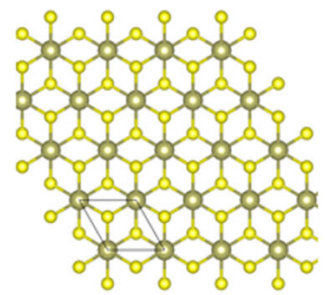

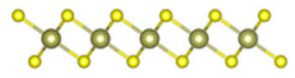

$\int^{2} \sigma^{2} \sigma^{2} \sigma^{0}$

Chalcogen
h-BN

$0-\infty-\infty-\infty-\infty$

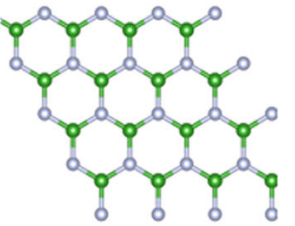

$\infty=\infty-\infty+\infty=\infty \quad A^{\prime}$

$0=-\infty=-\infty=\infty=-\infty$

A

Fig. 4

which replaces the previous incorrect version:

$2 \mathrm{H}$

a.

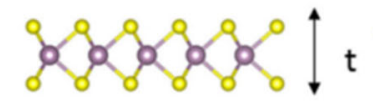

b.

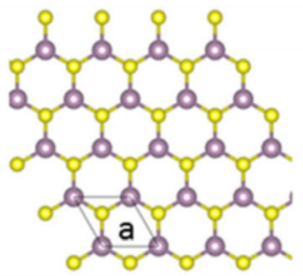

c.

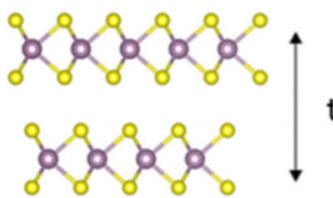

Metal
$1 T$
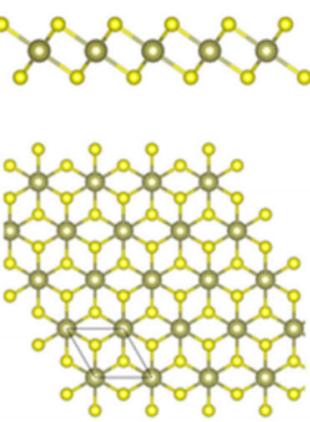

$\int_{0}^{2} \sigma^{2} \sigma^{2}$

$\sigma^{2} \sigma^{2} \sigma^{2} \sigma^{\circ}$

Chalcogen
h-BN

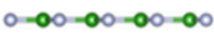

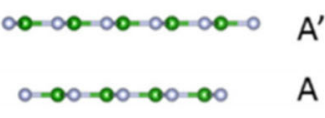

Boron
After the sentence "Bilayer h-BN stacked in A-A' order" in the legend for Fig. 4, the following sentence has been added: " $a$ is the in-plane lattice constant whereas $t$, the distance between the metal atom planes in the bilayer structure, corresponds to the monolayer thickness".

These have been corrected in both the PDF and HTML versions of the Article.

Open Access This article is licensed under a Creative Commons Attribution 4.0 International License, which permits use, sharing, adaptation, distribution and reproduction in any medium or format, as long as you give appropriate credit to the original author(s) and the source, provide a link to the Creative Commons license, and indicate if changes were made. The images or other third party material in this article are included in the article's Creative Commons license, unless indicated otherwise in a credit line to the material. If material is not included in the article's Creative Commons license and your intended use is not permitted by statutory regulation or exceeds the permitted use, you will need to obtain permission directly from the copyright holder. To view a copy of this license, visit http://creativecommons. org/licenses/by/4.0/.

(c) The Author(s) 2020 